\title{
VIBRATIONAL SPECTRA OF ORDERED PEROVSKITES
}

\author{
A. F. CORSMIT, H. E. HOEFDRAAD and G. BLASSE \\ Solid State Chemistry Department, University of Utrecht, Utrecht, The Netherlands
}

(Received 28 Janurary 1972)

\begin{abstract}
The vibrational spectra of the molecular $\mathrm{M}^{6+} \mathrm{O}_{6}(\mathbf{M}=\mathrm{Mo}, \mathrm{Te}, \mathrm{W})$ group in ordered perovskites of the type $\mathrm{Ba}_{2} \mathrm{M}^{2+} \mathbf{M}^{6+} \mathrm{O}_{6}$ are reported. These groups have symmetry $\mathrm{O}_{h}$, whereas their site symmetry is also $\mathrm{O}_{h}$. An assignment of the internal vibrations is presented.
\end{abstract}

\section{INTRODUCTION}

THE VIBRATIONAL spectra of octahedral anionic groups in solids are usually considered to be more complex than those of the analogous tetrahedral groups (see e.g. Refs. $[1,2])$. Remembering the successful efforts to interpret the vibrational spectra of molecules like $\mathrm{SF}_{6}$ in the gaseous or liquid phase [3] it seems tempting to start investigations on regular octahedral anionic groups in solids with high symmetry. A very suitable crystal structure for this purpose is the ordered perovskite structure [4]. This structure has been found for e.g. $\mathrm{Ba}_{2} \mathrm{CaWO}_{6}$. In this compound the $\mathrm{WO}_{6}$ octahedra are regular, i.e. $\mathrm{O}_{h}$ symmetry, the field at the octahedral group has also $\mathrm{O}_{h}$ symmetry, and in addition, the $\mathrm{WO}_{6}$ octahedra do not have oxygen ions in common. Each primitive unit cell contains one tungstate group only. In this paper the vibrational spectra of $\mathrm{Ba}_{2} \mathrm{CaMoO}_{6}, \mathrm{Ba}_{2} \mathrm{CaTeO}_{6}, \mathrm{Ba}_{2} \mathrm{CaWO}_{6}$ and $\mathrm{Ba}_{2} \mathrm{MgWO}_{6}$ are presented. To our knowledge only Hauck [5] has published i.r. data on compounds of this type. These, however, are incomplete.

\section{EXPERIMENTAL}

Samples were prepared by usual techniques (see e.g. Refs $[4,6]$. Starting materials were high-purity $\mathrm{BaCO}_{3}, \mathrm{CaCO}_{3}, \mathrm{MgCO}_{3}, \mathrm{MoO}_{3}, \mathrm{TeO}_{2}$ and $\mathrm{WO}_{3}$. Final firing was carried out in air or $\mathrm{O}_{2}$ at $1200^{\circ} \mathrm{C}$ or higher. Samples were checked on a Philips X-ray diffractometer using $\mathrm{Cu} K \alpha$ radiation.

I.R. spectra were recorded on a Hitachi EPI-G3 grating spectrometer (down to $400 \mathrm{~cm}^{-1}, \mathrm{KBr}$ pellets) and a Grubb Parsons DM 4 spectrometer with a CsI-prism (down to $200 \mathrm{~cm}^{-1}$, CsI-pellets).

Raman spectra were recorded on a Spectra Physics 700 Raman spectrometer using an argon ion laser. All measurements were carried out at room temperature.

\section{RESULTS}

In Fig. 1 the Raman spectra of $\mathrm{Ba}_{2} \mathrm{CaWO}_{6}$ and $\mathrm{Ba}_{2} \mathrm{CaTeO}_{6}$ are presented. The intensity of the Raman band at about $650 \mathrm{~cm}^{-1}$ was extremely low in the case of the molybdate and the tungstates.

1. G. M. Clark and W. P. Doyle, Spectrochim. Acta 22, 1441 (1966).

2. P. Tarte and F. Leyder, C.r. Acad. Sci., Paris, Série C, 273, 852 (1971).

3. G. Herzberg, Infrared and Raman Spectra. D. van Nostrand, New York (1945).

4. E. G. Steward and H.P. Rooksby, Acta Crystallogr. 4, 503 (1951).

5. J. Hauck, Z. Naturf. 25b, 224 (1970).

6. G. Bayer, J. Am. ceram. Soc. 46, 604 (1963). 

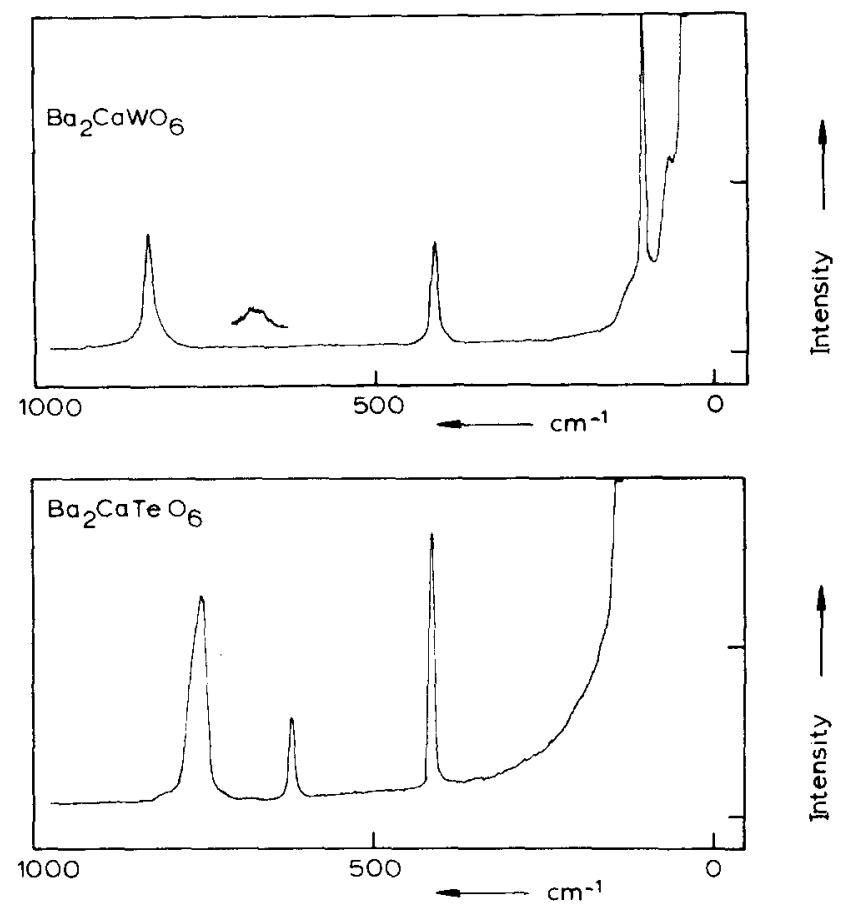

Fig. 1. Raman spectra of $\mathrm{Ba}_{2} \mathrm{CaWO}_{6}$ and $\mathrm{Ba}_{2} \mathrm{CaTeO}_{6}$. The inset around $675 \mathrm{~cm}^{-1}$ in the case of $\mathrm{Ba}_{2} \mathrm{CaWO}_{6}$ has been enlarged by a factor of 20 .

The i.r. spectra show three bands. The strong band in the region $600-700 \mathrm{~cm}^{-1}$ shows clearly a shoulder. In the far i.r. region $\left(200-400 \mathrm{~cm}^{-1}\right)$ two distinct bands are observed.

In Table 1 the frequencies corresponding to the maxima of the vibrational bands are given.

We further noted that part of the compounds under investigation, viz. $\mathrm{Ba}_{2} \mathrm{CaMoO}_{6}$ and $\mathrm{Ba}_{2} \mathrm{CaWO}_{6}$ react violently with water under the formation of $(\mathrm{Ba}, \mathrm{Ca}) \mathrm{MoO}_{4}$ or $(\mathrm{Ba}, \mathrm{Ca}) \mathrm{WO}_{4}$ and $(\mathrm{Ba}, \mathrm{Ca})(\mathrm{OH})_{2}$. The compound $\mathrm{Ba}_{2} \mathrm{CaTeO}_{6}$ reacts much slowlier, whereas $\mathrm{Ba}_{2} \mathrm{MgWO}_{6}$ does not react at all. This decomposition is of importance if the $\mathrm{KBr}$ and CsI used for the pellet-technique is not completely dry.

Table 1. Vibrational spectra of ordered perovskites $\left(\mathrm{cm}^{-1}\right)$

\begin{tabular}{lcccccc}
\hline Compound & \multicolumn{3}{c}{ Raman } & & \multicolumn{3}{c}{ Infrared } \\
\hline $\mathrm{Ba}_{2} \mathrm{CaMoO}_{6}$ & $812(\mathrm{~s})$ & $650(\mathrm{vw})$ & $416(\mathrm{~m})$ & $598(\mathrm{~s} . \mathrm{sh})$ & $357(\mathrm{~s})$ & $292(\mathrm{~s})$ \\
$\mathrm{Ba}_{2} \mathrm{CaTeO}_{6}$ & $752(\mathrm{~s})$ & $618(\mathrm{~m})$ & $412(\mathrm{~s})$ & $685(\mathrm{~s} . \mathrm{sh})$ & $400(\mathrm{~s})$ & $284(\mathrm{~s})$ \\
$\mathrm{Ba}_{2} \mathrm{CaWO}_{6}$ & $832(\mathrm{~s})$ & $675(\mathrm{vw})$ & $410(\mathrm{~s})$ & $628(\mathrm{~s} . \mathrm{sh})$ & $327(\mathrm{~s} . \mathrm{sh})$ & $289(\mathrm{~m})$ \\
$\mathrm{Ba}_{2} \mathrm{MgWO}_{6}$ & $817(\mathrm{~s})$ & $680(\mathrm{vw})$ & $444(\mathrm{~s})$ & $622(\mathrm{~s})$ & $388(\mathrm{~s})$ & $319(\mathrm{~m})$ \\
$\mathrm{Assignments}$ & $\nu_{1}$ & $\nu_{2}$ & $\nu_{5}$ & $\nu_{3}$ & $\nu_{4}$ & \\
\hline
\end{tabular}

(s): strong, (m): medium, (vw): very weak, (sh): shoulder. 


\section{DISCUSSION}

We assume that the binding forces in the $\mathrm{M}^{6+} \mathrm{O}_{6}$ octahedron are large compared with the crystal-binding forces. In that case the frequencies of the internal vibrations of this group in the solid ought to be close to the frequencies of the free-ion modes. Furthermore, the external modes ought to lie at lower frequencies then the internal modes. Group theoretical considerations represent the normal vibrations of an octahedral molecule as

$$
A_{1 g}+E_{g}+2 T_{1 u}+T_{2 g}+T_{2 u} \text {. }
$$

The modes $A_{1 y}, E_{g}$ and $T_{2 g}$ are Raman-active, the two modes $T_{1 u}$ i.r.-active, whereas $T_{2 u}$ is inactive. Since there is only one $\mathrm{M}^{6+} \mathrm{O}_{6}$ group per primitive unit cell we expect three bands in the Raman and two in the i.r. spectra.

Our Raman spectra show in fact three bands if we neglect a number of bands at very low wavenumbers (external modes). The strong Raman line with the highest frequency is assigned to $\nu_{1}\left(A_{1 g}\right)$, the line with the lowest frequency to $\nu_{5}\left(T_{2 g}\right)$. In between these two we find $\nu_{2}\left(E_{g}\right)$ with very low intensity in the case of $\mathrm{WO}_{6}$ and $\mathrm{MoO}_{6}$. Woodward et al. $[7,8]$ have drawn attention to strong variations of the intensity of the $\nu_{2}\left(E_{g}\right)$ vibration. They related these variations to differences in bonding type.

The ratio of the intensity $I_{1}$ of $\nu_{1}$ to $I_{2}$ of $\nu_{2}$ can be given by

$$
\frac{I_{1}}{I_{2}}=\frac{5 A_{1}\left[1+\left(2 \alpha_{p}^{\prime} / \alpha_{l}^{\prime}\right)\right]^{\prime 2}}{13 A_{2}\left[1-\left(\alpha_{p}^{\prime} / \alpha_{l}^{\prime}\right)\right]^{\prime 2}}
$$

where $A_{1}=\left(\nu_{0}-v_{1}\right)^{4} / \nu_{1}\left[1-\exp \left(-h \nu_{1} / k T\right)\right], \nu_{0}$ being the exciting frequency [7].

Further $\alpha_{l}^{\prime}$ and $\alpha_{p}^{\prime}$ are the derived bond polarizabilities with respect to bond stretching along and perpendicular to the bond direction respectively.

A high value of $I_{1} / I_{2}$ as observed for the $\mathrm{WO}_{6}$ and $\mathrm{MoO}_{6}$ group indicates a value of $\alpha_{p}^{\prime} / \alpha_{l}^{\prime}$ approaching one. This can be realized only if the amount of $\pi$-bonding is considerable. We can expect that in the case of $\mathrm{W}^{6+}$ and $\mathrm{Mo}^{i+}$ with $p^{i}$ configuration, i.e. with low-lying empty $t_{2 g}-d$ orbitals, $\pi$-bonding is of more importance than in the case of $\mathrm{Te}^{6+}$ with $d^{10}$ configuration. This has been applied by one of us in structural considerations on oxides with cations of these types [9]. We, therefore, assume that the low intensity of the $\nu_{2}$ vibration is another indication of the importance of $\pi$-bonding in the case of highly-charged cations with noblegas configuration in octahedral coordination. In accordance with this a very low intensity of $\nu_{2}$ has been observed for the $\mathrm{Nb}^{5+} \mathrm{Cl}_{6}$ and $\mathrm{Ta}^{\mathrm{j}+} \mathrm{Cl}_{6}$ octahedra[10]. In $\mathrm{K}_{.2} \mathrm{NiF}_{6}$, however, $\nu_{2}$ has an intensity roughly equal to that of $\nu_{1}[11]$. In the $\mathrm{Ni}^{1+} \mathrm{F}_{6}$ group $\pi$-bonding cannot be important because the $t_{2, y}$ orbitals are completely filled $\left(\mathrm{Ni}^{+1+}\right.$ has $d^{6}$ low-spin configuration).

We now turn to the i.r. spectra. Two bands are expected, viz. $\nu_{3}\left(T_{11}\right)$ and ${ }_{1},\left(T_{1 u}\right)$. In fact we find three bands. The two bands at higher frequency are assigned to $\nu_{3}$ and $\nu_{4}$ (see Table 1). The band around $300 \mathrm{~cm}^{-1}$ is ascribed to an

7. L. A. Woodward and J. A. Creighton, Spectrochim. Acta 17, 594 (1961).

8. L. A. Woodward and N. J. Ware, Spectrochim. Acta 19,775 (1963).

9. G. Blasse.J. inorg. nucl. Chem. 26, 1191 (1964) and 27, 2117 (1965).

10. W. van Bronswijck. R. J. H. Clark and L. Maresca, Inorg. ( $/ / e m .8$. 1395 (1969). 
external vibration. It is not impossible that this vibration belongs to the $\mathrm{M}^{2+} \mathrm{O}_{6}$ octahedron. Evidence for these assignments comes from the following facts

(a) If $\mathrm{M}^{2+}=\mathrm{Ca}^{2+}$ the latter frequency is nearly independent of the choice of $\mathrm{M}^{6+}$ (in contradistinction to the other frequencies).

(b) Tarte [12] gives the region $300-450 \mathrm{~cm}^{-1}$ for the i.r. absorption of the $\mathrm{MgO}_{6}$ octahedron in oxides. Our value of $319 \mathrm{~cm}^{-1}$ is within this range.

(c) In $\mathrm{K}_{2} \mathrm{NiF}_{6}$ with the same structure $\left(\mathrm{Ni}^{4+}\right.$ on the $\mathrm{M}^{6+}$ sites, but a vacancy on the $\mathrm{M}^{2+}$ sites) only two i.r. bands have been observed [11].

The fact that at least part of the i.r. bands of the $\mathrm{M}^{6+} \mathrm{O}_{6}$ group show a shoulder seems to indicate deviations from pure cubic symmetry. Our X-ray diagrams do not show evidence for this. It is a well-known fact, however, that pseudo-cubic perovskites can show serious deviations from cubic symmetry at the octahedral cation-sites (see e.g. Ref.[13]). In order to study this problem further the present work is now extended to ordered perovskites with serious deviations from cubic symmetry.

Acknowledgements - The authors are indebted to Dr. J. H. van der Maas (Analytical Laboratory of this University) for the performance of the Raman measurements and to Drs. R. Elst (University of Amsterdam) and Mr. G. J. Dirksen for some introductory experiments.

11. M. J. Reisfeld, Molec. Spectrosc. 29, 120 (1969).

12. P. Tarte, Spectrochim. Acta 18, 467 (1962).

13. S. Geller and E. A. Wood, Acta crystallogr. 9,563 (1956). 